\title{
The Aesthetic Education Value of Thematic Art Creation
}

\author{
Yingying Cui* \\ Weinan Normal University, Weinan 714099, China \\ *Corresponding author: Yingying Cui, 39885082@qq.com
}

\begin{abstract}
Thematic art creation is a product of a complex social, historical, and cultural context, and it fills an important position in the development of modern and contemporary Chinese art history. Since the 21 st century, with the introduction and implementation of a series of national major thematic art creation projects, thematic art creation has gradually moved from a marginal position in art history to a core area, becoming a visual narrative method with independent aesthetic value. Moving towards cultural consciousness and carrying cultural self-confidence, thematic art creation requires the guidance, standardization, and support of related art theories. The lack and absence of theoretical research restricts the development of thematic art creation. This study combs through the research results and literature materials of thematic art creation since the new century as well as studies the aesthetic education value of thematic art creation image narration.
\end{abstract}

Keywords: Thematic art creation; Aesthetic education value; Image narration; Aesthetic consciousness

Publication date: December 2021; Online publication: December 27, 2021

Thematic art creation is an expression of aesthetic narration of historical reality, and it is a product of a complex social, historical, and cultural context. With the deepening of reform and opening-up as well as the substantial improvement of the country's comprehensive strength, the Chinese culture has gradually shown a conscious and confident development direction. As a sub-system of the cultural system, art cannot be absent from the active construction of the historical process of the cultural revival of the Chinese nation in the new era. Since the 21st century, with the introduction and implementation of a series of national major thematic art creation projects, thematic art creation has gradually moved from a marginal position in art history to a core area, and it has become a visual narrative with independent aesthetic value in the history of Chinese art development.

In regard to the thematic art creation in modern China, Chinese paintings, oil paintings, prints, sculptures, and many other forms of expressions constitute an eye-catching visual epic narration; the theoretical research of thematic art creation requires sociology, politics, and aesthetics, supported by a series of theoretical disciplines, such as art criticism and stylistics. On the one hand, art creation and theoretical research should be both external and internal. A value system should be established for thematic art creation research. On the other hand, theoretical research should be the forerunner of thematic art creation toward cultural awareness and the promotion of cultural self-confidence. Time-sensitive theoretical responses should be made by combing through traditional creative experience and summarizing the problems as well as the phenomena in creative practice.

Thematic art creation generally refers to the creation of historical paintings in a traditional sense. The current "thematic art creation" revolves around the 70th anniversary of the victory in the Anti-Japanese War, the 80th anniversary of the victory in the Red Army's Long March, the 90th anniversary of the founding of the army, and the 19th anniversary of the Communist Party of China. The National Congress 
was successfully held, the 200th anniversary of Marx's birth, the 40th anniversary of reform and openingup, poverty alleviation, and a well-off society, the 100th anniversary of the founding of the Communist Party of China, and other major historical events of the party as well as the country. The features include the construction of an open pattern, the extension of classic themes, the inheritance of civilization and context, the reshaping of character connotations, the extension of language styles, and the transcendence of ideological journeys. Compared with the famous historical painting creation, the current thematic art creation is based on the national system and presents the characteristics of collectivist aesthetics and nationalist aesthetics; it is already shouldering the responsibility of constructing an interdisciplinary research system, promoting positive behaviors and social aesthetic orientation, as well as expanding artistic expression media, along with other various cultural missions ${ }^{[1]}$.

In the context of globalization, thematic art creation has become a unique artistic phenomenon in China. It maintains the inherent impulse to construct and write history in the form of image narrative. Throughout the development of world art history and artistic trends, Western art rejects "historical painting" as a sign of entering modernity, and the only way to transform Chinese art is to insist on the realistic aesthetic construction of history. As an aesthetic narration of historical reality, in the process of moving from the cultural field to cultural consciousness and promoting cultural self-confidence, thematic art creation needs the guidance, standard, and support of related art theories. The academic discussion of thematic art creation in the art world can be traced back to the 21st Century China Thematic Art Creation Seminar; in recent years, scholars have devoted themselves to the research of this high-frequency topic and academic hotspot - thematic art creation. The study of creation began a conscious journey of theoretical research and icebreaking in the suspension of the conceptual connotation established by the convention. The lack and absence of theoretical research in related fields restrict the development of thematic art creation ${ }^{[2]}$.

It has been repeatedly emphasized, "Culture is the soul of a country and a nation. Culture rejuvenates the country and strengthens the nation. Without a high degree of cultural self-confidence and cultural prosperity, there would be no great rejuvenation of the Chinese nation." Cultural self-confidence has become a symbol of life of the country, and the importance of art as a part of the cultural system cannot be disregarded. Thematic art creation is the most eye-catching cultural creation form since the 21 st century, and it has become a way of image narration towards cultural consciousness and cultural self-confidence.

Thematic art creation has a long history and profound cultural tradition. Although different countries and nationalities have different perceptions of the concept, category, and connotation of thematic art creation in different historical periods, there are artistic phenomena of using image narrative to record real life and spiritual life.

In the history of ancient Chinese art, "historical paintings" were called "GuShi Paintings." The term "GuShi" was first seen in "Guoyu·Zhou Yushang": "To execute punishment, one must ask about the legacy and the story." Xie He of the Southern Qi Dynasty clearly mentioned the enlightenment function of "GuShi Paintings" in The Record of Ancient Paintings: "The painter, never knowing the exhortation, is deep and potentially lonely, and criticizes pictures for reference." In the Famous Paintings of Past Dynasties, Zhang Yanyuan of the Tang Dynasty clearly said, "Paint, become educated, help others, change spirits, measure the subtle." From a functional point of view in ethical education, "GuShi Paintings" is as important as the Six Classics of Confucianism; from the perspective of expressing natural functions, it is consistent with the laws of heaven and earth movement. Therefore, in ancient China, whether it is based on the concept of life and death as the leading stone, portrait bricks, mural sculptures serving religious beliefs, or historical paintings serving political rulings, all of them have the purpose of propaganda and enlightenment. From the portraits of the heroes of Kylin Pavilion in the Han Dynasty to "Nu Shizheng" and the Book of Northern $Q i$ in the Southern and Northern Dynasties, respectively; from "BuNian" and the "Portraits of Emperors of Successive Dynasties" in the Tang Dynasty to "Qingming Shanghe" and "Jin Wengong" in the Song 
Dynasty; from the emperor's statues, rules, and remonstrance paintings in the early Ming Dynasty to "Wanshu Garden" and "Gusu Prosperity" in the Qing Dynasty; all of them played a role of remonstrance [3].

In the history of modern Chinese art, thematic art creation has gone through several important development stages. After the Republic of China, a large number of western painting concepts poured in and Kang Youwei, Chen Duxiu, and others voiced for the reform of Chinese paintings. During the first two decades of the Republic of China, the Chinese painting circle was in a stage of reform and exploration, and thematic art creation was at a low ebb. The first stage of thematic art creation was from the 1930s to the founding of the nation. At the critical moment of national peril, saving the nation from the extinction was the primary task of the government, all parties, and the people. Reflecting the reality of the Anti-Japanese War, awakening patriotic feelings and stimulating enthusiasm towards the Anti-Japanese War are the core themes of art creation in a specific historical context. The various categories of fine arts give full play to their own characteristics and advantages, whether it is Liu Kaiqu's sculpture, "Unknown Hero," Xu Beihong's oil painting, "Tian Heng Five Hundred Scholars," or the emerging prints advocated by Lu Xun, such as Gu Yuan's "Rent Reduction Meeting" and Jiang Zhaohe's painting, "The Refugee Picture"; both of these artworks reflect strong revolutionary, propagandizing, narrative, and documentary nature. The second stage was during the 1950s and 1960s, which can be said to be the peak of Chinese thematic creation. Artists, at this stage, have an infinite vision for a new China, with creative enthusiasm, using a wealth of artistic media and forms of expressions to express China's brand-new look, construction achievements, and major historical events that have shaped the image of heroes in the history of China's revolution. The third stage falls in the beginning of the new century. With the gradual transformation of the world structure, the substantial increase of China's comprehensive national strength, and the continuous enhancement of cultural consciousness as well as self-improvement, a series of major national-level art creation projects with spectacular thematic art creations have been launched along with the emerging of modern Chinese, which caused a boom in art history, such as the "National Major Historical Theme Art Creation Project," the "Chinese Civilization History Theme Art Creation Project," "Celebrating the 90th, 95th, and 100th Anniversary of the Founding of the Communist Party of China National Art Exhibition," the "Major Thematic Sculpture Project of the Chinese Communist Party History Exhibition Hall," and other thematic art creation projects, co-organized by the Central Propaganda Department, the Ministry of Culture, the Chinese Federation of Literary and Art Associations, as well as the Chinese Artists Association in reconstructing cultural memory and writing in an aesthetic national epic narrative way.

Through the comparative study of the above three major thematic art creation booms, it can be appreciated that thematic art creations in different historical periods have different expression methods, social contexts, and value orientations. If the thematic art creation in the first stage was the result of the appeals of art clubs and the conscious participation of artists, then, the reason for the active thematic art creation in the second stage is the government's vigorous advocacy and the full support of art institutions; in the third stage, the thematic art creation boom is centered on the strong desire for national prosperity and cultural construction, having the characteristics of being based on the national system. Compared with famous historical painting creations in history, the current thematic creation is based on national power, with huge scale, abundant human and financial resources, complex contents, and diverse styles. It has become a cultural phenomenon almost unique in the era of globalization. Since the mid-20th century, no country or nation has maintained the internal impulse to construct history like China. It can be seen that the path of modernity between Chinese art and Western art is quite different: when Western art rejects "historical paintings" as a sign of modernity, Chinese art does the opposite and insists on major thematic art creation projects; when Western artists focus on personal philosophical thinking and pursue more personalized art form creation and emotional expression, Chinese artists integrate individualized aesthetic 
pursuits into the construction of collectivist aesthetic consciousness. Thematic art creation is the product of aesthetic narration and image construction. As an image text, it transcends the textual description of historical events and becomes the spiritual visual representation of the nation, the country, and the era ${ }^{[4]}$.

The sociological value of thematic art creation lies in the poetic or philosophical interpretation of life by means of expression. Subjective art creation is intertwined with a complex socio-historical and cultural context. The so-called "representation" is not a "reproduction" of social life and historical reality, but it is an expressive narrative of real characters and historical events based on in-depth experience of life. Artists should preserve today's images for the future and store cultural memories for the present. The purpose of thematic art creation is not only to look back at history and reproduce reality, but more importantly, to present the historical feelings and cultural attitudes of this generation of artists to the world and future generations.

\section{Disclosure statement}

The author declares that there is no conflict of interest.

\section{References}

[1] Yu Y, 2017, Only Expansion Can Surpass - The Connotation Category and Future Opportunities of Thematic Art Creation. Art Observation, 2017(1): 77-78.

[2] Shang H, 2011, Art Creation with Historical Themes in Openness and Diversification. Art Review, 2011(7): 56-57.

[3] Du S, 2016, Historical Aesthetic Narration and Value Construction - Thinking on Several Theoretical Issues of Artistic Creation of Important Historical Themes. Journal of Historical Science, 2016(12): 65-66.

[4] Zhang X, 2016, Historical Aesthetic Narration and Image Construction. China Art News. February 1, 2016. 